\title{
Seleksi Lima Isolat Fungi Mikoriza Arbuskular untuk Pembibitan Kelapa Sawit (Elaeis guineensis Jacq.) pada dua Dosis Pupuk NPK
}

\section{Selection of Five Types Isolate Arbuscular Mycorrhizal Fungi for Oil Palm Seedling (Elaeis guineensis Jacq.) on Two Dose NPK Fertilize}

\author{
Retta Ramadhina Rias ${ }^{1}$, Maria Viva Rini ${ }^{2}$, dan Fitri Yelli ${ }^{2}$ \\ ${ }^{1}$ Mahasiswa Jurusan Agoteknologi Fakultas PertanianUniversitas Lampung \\ ${ }^{2}$ Dosen Jurusan Agoteknologi Fakultas PertanianUniversitas Lampung \\ Jln. Prof Soemantri Brodjonegoro No.1 Bandar Lampung 35143 \\ Korespondensi: rettaramadhinarias@yahoo.com
}

\begin{abstract}
Oil palm (Elaeis guineensis Jacq.) in Indonesia commonly cultivated on land that is classified as marginal land such as soil type ultisol with a low fertility rate, so it is necessary to improve the quality of seeds with the use of arbuscular mycorrhiza fungi (AMF) and NPK fertilizers. This study aimed (1) to determine the most appropriate type of AMF for oil palm seedling, (2) to determine the dose of NPK fertilizeris best for the growth of oil palm seedlings, (3) to determine whether the response of oil palm seedling stobe determined by the type of NPK fertilizer, (4) to determine the best dose of NPK fertilizer for each type of AMF. Research compiled using factorial treatment design (6 62$)$ with 5 replications. The first factor is the type of mycorrhizal (M) which consists of 6 levels iem l $_{0}$ (without AMF), $m_{1}$ (Entrophospora sp. Isolates MV 3 ), $m_{2}$ (Entrophospora sp. Isolates MV12), $m_{3}$ (Glomus sp. Isolates MV 4), $m_{4}$ (Glomus sp. Isolates MV11), and $m_{5}($ Glomus sp. Isolates MV13). The second factoris the dose of NPK fertilizer $(P)$ which consists of 2 level p1 (100\% of the recommended dose), p2 (75\% of the recommended dose). The similarity of variance between treatments were tested with Least Significant Differencetest (LSD) at 5\% significance level. The results showed (1) All types of FMA being tested can increase the growth of oil palm seedlings compared without exception AMF Glomus sp. MV isolates 11, (2) dose of NPK fertilizer 100\% of recommended doses produce the best growth of oil palm seedlings shown by the fresh weight of shoot, dry weight of shoot, fresh weight of root, dry weight of root,and leaf greenness level, (3) palm seedling growth response to AMF inoculationis not determined by a given dose of NPK fertilizer, (4) there is no optimum dose of NPK fertilizer for each type of AMF were used.
\end{abstract}

Keywords :Arbuscular mycorrhizal fungi, dose NPK fertilize, oil palm seedling.

Diterima: 15 Oktober 2014, disetujui 19 Desember 2014 
Retta Ramadhina Rias: Seleksi Lima Isolat Fungi Mikoriza Arbuskular untuk Pembibitan Kelapa Sawit...

\section{PENDAHULUAN}

Indonesia merupakan salah satu produsen utama minyak sawit (Fauzi et al., 2012). Saat ini Indonesia merupakan produsen minyak sawit mentah (CPO) terbesar di dunia. Pada tahun 2012, luas lahan perkebunan di Indonesia mencapai 9 juta ha dengan produksi CPO 24 juta ton per tahun. Produksi ini dikonsumsi di dalam negeri sebesar 5 juta ton, sementara $80 \%$ sisanya di ekspor. Lampung memiliki lahan perkebunan kelapa sawit dengan luasan 118.634 ha pada tahun 2012, dengan produksi CPO sekitar 401.052 ton (Direktorat Jendral Perkebunan, 2012). Kendala pengembangan kelapa sawit di Indonesia adalah langkanya lahan subur dan biaya pemeliharan khususnya pemupukan yang relatif tinggi. Lahan pengembangan kelapa sawit banyak diusahakan pada lahan yang tergolong lahan marginal dengan tingkat kesuburan yang rendah (Hardjowigeno, 1993). Sebagian besar tanah di Indonesia meliputi tanah Ultisol yang mempunyai sebaran sangat luas. Hampir 25\% dari total daratan Indonesia (Kementrian Pertanian, 2010).

Dewasa ini mulai dikembangkan pemanfaatan mikrooganisme yang bermanfaat khususnya Fungi Mikoriza Arbuskular (FMA). Sebagai alternatif mengatasi masalah ketersediaan unsur hara khususnya $\mathrm{P}$, sebagai unsur hara makro. Fungi Mikoriza Arbuskula pada lahan marginal yang miskin unsur hara mampu meningkatkan penyerapan hara makro (terutama P) dan hara mikro melalui hifa eksternalnya (Simanungkalit, 2004). Fungi Mikoriza Arbuskular merupakan asosiasi antara fungi dengan akar tanaman yang membentuk jalinan interaksi yang kompleks dan memiliki kemampuan berasosiasi hampir dengan $90 \%$ tanaman dan membantu tanaman dalam meningkatkan efisiensi penyerapan unsur hara terutama fosfor (Anas, 1989).

Penelitian ini bertujuan untuk (1) menentukan jenis FMA yang paling sesuai untuk pembibitan kelapa sawit, (2) menentukan dosis pupuk NPK yang paling baik untuk pertumbuhan bibit kelapa sawit, (3)mengetahui apakah respon bibit kelapa sawit terhadap jenis FMA ditentukan oleh dosis pupuk NPK, (4)menentukan dosis pupuk NPK terbaik untuk masing-masing isolat FMA

\section{METODE}

Penelitian dilaksanakan di Laboratorium Produksi Perkebunan, rumah kaca Fakultas Pertanian Universitas Lampung, dan lahan Politeknik Negeri Lampung dari bulan Mei 2013 sampai Februari 2014. Alat - alat yang digunakan adalah mikroskop stereo dan majemuk, timbangan elektrik, pinset spora, cawan petri, saringan mikro (ukuran $500 \mu \mathrm{m}, 63 \mu \mathrm{m}$, dan $45 \mu \mathrm{m}$ ), gelas ukur, cangkul, counter, polibag, cutter, ember, gembor, oven, cover glass, kaca preparat, dan alat tulis. Bahan - bahan yang digunakan adalah germinated seed kelapa sawit varietas Tenera Simalungun, pasir, tanah, aquades, larutan $\mathrm{KOH}$ 10\%, HCL 1\%, glycerol,trypan blue, pupuk "Rock phosphate", Urea, NPK, dan mikoriza yaitu Glomus sp. dan Entrophospora sp.

Perlakuan disusun dalam rancangan perlakuan faktorial $(6 \times 2)$ dengan 5 ulangan. Faktor pertama adalah jenis mikoriza (M) yang terdiri dari 6 taraf yaitu $\mathrm{m}_{0}$ (Kontrol), $\mathrm{m}_{1}$ (Entrophospora sp., Isolat MV 3), $\mathrm{m}_{2}$ (Entrophospora sp., Isolat MV 12), $\mathrm{m}_{3}$ (Glomus sp., Isolat MV 4), $\mathrm{m}_{4}$ (Glomus sp., Isolat MV 11), dan $\mathrm{m}_{5}$ (Glomus sp., Isolat MV 13). Faktor kedua adalah dosis pupuk NPK (P) yang terdiri dari 2 taraf yaitu $\mathrm{p}_{1}$ (100\% dari dosis anjuran), $\mathrm{p}_{2}$ (75\% dari dosis anjuran). Adapun masingmasing isolat yangdigunakan dapat dilihat pada Tabel 1. 
Jurnal Penelitian Pertanian Terapan

Tabel 1. Deskripsi Fungi Mikoriza Arbuskular.

\begin{tabular}{llll}
\hline Spesies & Isolat & Asal Daerah & Tanaman Inang \\
\hline Entrophospora sp. & MV3 $\left(\mathrm{m}_{1}\right)$ & Lampung & Kelapa Sawit \\
Entrophospora sp. & $\mathrm{MV} 12\left(\mathrm{~m}_{2}\right)$ & Medan & Kelapa Sawit \\
Glomus sp. & $\mathrm{MV4}\left(\mathrm{m}_{3}\right)$ & Lampung & Kelapa Sawit \\
Glomus sp. & $\mathrm{MV11}\left(\mathrm{m}_{4}\right)$ & Lampung & Kelapa Sawit \\
Glomus sp. & $\mathrm{MV} 13\left(\mathrm{~m}_{5}\right)$ & Jember & Jarak Pagar \\
\hline
\end{tabular}

Kesamaan ragam antar perlakuan diuji dengan Uji Barlett. Kemenambahan data diuji dengan Uji Tukey. Jika asumsi terpenuhi yaitu ragam perlakuan homogen dan data bersifat menambah, data dianalisis ragam. Pemisahan nilai tengah diuji dengan Uji Beda Nyata Terkecil (BNT) dengan peluang melakukan kesalahan ditentukan sebesar 0,05.

\section{Penyemaian benih}

Benih kelapa sawit yang baru kecambah disemai pada media persemaian menggunakan pasir steril selama 4 minggu kemudian ditransplanting ke pre nursery.

\section{Penyiapan media tanam di Pre-nursery dan Main Nursery}

Media tanam yang digunakan pada saat di pre-nursery adalah tanah yang tidak steril dan bahan organik dengan perbandingan bahan organik 7:1. Kedua media dicampur hingga rata, kemudian ditambahkan pupuk Rock Phospat sebanyak 100 g untuk 60 polibag pre-nursery lalu dicampur hingga homogen. Sedangkan media tanam yang digunakan pada main-nursery adalah tanah top soil yang tidak disterilkan.

\section{Penanaman di Pre-nursery dan inokulasi spora FMA}

Benih yang telah disemai selama 4 minggu, dipindah tanam dalam polibag yang berukuran 18 x $25 \mathrm{~cm}$ dengan satu bibit per polibag. Inokulum FMA ditaburkan secara merata dan perlahan pada akar-akar bibit dengan dosis \pm 500 spora/bibit, sehingga inokulum tersebar merata dipermukaan akar. Polibag-polibag yang sudah ditanami bibit dan diinokulasi dengan FMA sesuai perlakuan, kemudian disusun di dalam rumah kaca sesuai tata letak percobaan. Bibit dipelihara selama dua bulan sebelum di transplanting ke main nursery. Pemupukan dilakukan dengan menyemprotkan pupuk kepermukaan helai daun menggunakan pupuk urea dengan dosis $2 \mathrm{~g}$ per liter untuk 100 bibit.

\section{Penanaman di Main Nursery}

Transplanting bibit dari pre nursery ke main nursery dilakukan setelah bibit di pre nursery berumur 3 bulan setelah semai. Sebelum proses transplanting dilakukan, disiapkan polibag yang berisi tanah top soil sebanyak $20 \mathrm{~kg}$ tiap polibag. Lubang tanam dipolibag untuk main nursery dibuat sesuai dengan ukuran polibag di pre nursery agar bibit dapat ditransplanting tanpa merusak perakarannya dan memudahkan proses transplanting.

\section{Pemeliharaan tanaman}

Pemeliharaan bibit kelapa sawit yang dilakukan meliputi penyiraman, penyiangan gulma, pengendalian hama penyakit,dan pemupukan (Tabel 2). 
Retta Ramadhina Rias: Seleksi Lima Isolat Fungi Mikoriza Arbuskular untuk Pembibitan Kelapa Sawit...

Tabel 2. Jenis dan dosis pupuk yang digunakan selama penelitian.

\begin{tabular}{ccc}
\hline \multirow{2}{*}{ Umur bibit kelapa sawit ( minggu) } & Anjuran & Penelitian (75\% dari anjuran) \\
\cline { 2 - 3 } & NPK $15: 15: 15$ & NPK $15: 15: 15$ \\
\hline $14-15$ & $2,5 \mathrm{~g}$ & $1,875 \mathrm{~g}$ \\
$16-17$ & $5 \mathrm{~g}$ & $3,75 \mathrm{~g}$ \\
$18-20$ & $7,5 \mathrm{~g}$ & $5,625 \mathrm{~g}$ \\
$22-24$ & $10 \mathrm{~g}$ & $7,5 \mathrm{~g}$ \\
26 & $10 \mathrm{~g}$ & $7,5 \mathrm{~g}$ \\
28 & $10 \mathrm{~g}$ & $7,5 \mathrm{~g}$ \\
30 & $10 \mathrm{~g}$ & $7,5 \mathrm{~g}$ \\
32 & $10 \mathrm{~g}$ & $7,5 \mathrm{~g}$ \\
34 & $15 \mathrm{~g}$ & $11,25 \mathrm{~g}$ \\
36 & $15 \mathrm{~g}$ & $11,25 \mathrm{~g}$ \\
\hline
\end{tabular}

\section{Variabel Pengamatan}

Pengamatan dilakukan saat bibit berumur 36 minggu setelah semai. Untuk meguji kesahihan kerangka pemikiran dan hipotesis dilakukan pengamatan terhadap variabel-variabel tinggi tanaman, jumlah daun, tingkat kehijauan daun, bobot segar tajuk, bobot segar akar, bobot kering tajuk, bobot kering akar, jumlah akar primer, volume akar, persentase infeksi akar, dan jumlah spora.

\section{HASIL DAN PEMBAHASAN}

Hasil penelitian menunjukkan bahwa perlakuan jenis FMA pada pembibitan kelapa sawit berpengaruh nyata pada variabel tinggi tanaman, bobot segar tajuk, bobot segar akar, bobot kering tajuk, jumlah akar primer, volume akar, persen infeksi akar, dan jumlah spora. Dosis pupuk NPK untuk pembibitan kelapa sawit berpengaruh nyata pada variabel bobot segar akar, bobot kering tajuk, dan persen infeksi akar. Pengaruh interaksi antara jenis FMA dan dosis pupuk NPK tidak berpengaruh nyata pada seluruh variabel pengamatan (Tabel 3).

Tabel 3. Rekapitulasi analisis ragam data penelitian.

\begin{tabular}{lccc}
\hline \multicolumn{1}{c}{ Variabel Pengamatan } & & Perlakuan & \\
\cline { 2 - 4 } & FMA $(\mathrm{M})$ & Pupuk $(\mathrm{P})$ & $\mathrm{Mx}$ \\
\hline Tinggi tanaman & $*$ & tn & tn \\
Jumlah daun & tn & tn & tn \\
Tingkat kehijauan daun & tn & tn & th \\
Bobot segar tajuk & $*$ & tn & tn \\
Bobot segar akar & $*$ & $*$ & tn \\
Bobot kering tajuk & $*$ & tn & tn \\
Bobot kering akar & tn & tn & tn \\
Jumlah akar primer & $*$ & tn & tn \\
Volume akar & $*$ & $*$ & tn \\
Persen infeksi akar & $*$ & tn & \\
Jumlah Spora & $*$ & &
\end{tabular}

Keterangan: $\operatorname{tn}=$ tidak nyata pada $\alpha=5 \%$

$*$ nyata pada $\alpha=5 \%$

Hasil penelitian menunjukkan bahwa inokulasi FMA pada bibit kelapa sawit berpengaruh terhadap tinggi tanaman bibit kelapa sawit. Tinggi tanaman bibit kelapa sawit tertinggi diperoleh pada 
bibit yang diinokulasi Glomus sp. Isolat MV 13, Entrophospora sp. Isolat MV 12, Glomus sp. IsolatMV 4, dan Glomus sp. Isolat MV 11 berbeda nyata dengan tanpa mikoriza dan inokulasi Entrophospora sp. Isolat MV 3. Perlakuan pemupukan NPK pada dosis $100 \%$ dari dosis ajuran maupun $75 \%$ dari dosis anjuran tidak berbeda nyata terhadap tinggi tanaman bibit kelapa sawit yang tidak berbeda (Tabel 4). Hal ini didukung oleh penelitian Saputra (2011) yang menyatakan bahwa pemberian FMA Glomus sp. dapat menghasilkan tinggi bibit kelapa sawit yang tertinggi dibandingkan FMA jenis Entrophospora sp. dan tanpa mikoriza.

Tabel 4. Pengaruh perlakuan jenis FMA dan dosis pupuk NPK pada tinggi tanaman, jumlah daun, dan tingkat kehijauan daun bibit kelapa sawit umur 9 bulan.

\begin{tabular}{lccc}
\hline \multicolumn{1}{c}{ Perlakuan } & $\begin{array}{c}\text { Nilai Tengah Tinggi } \\
\text { Tanaman }\end{array}$ & $\begin{array}{c}\text { Nilai Tengah } \\
\text { Jumlah Daun }\end{array}$ & $\begin{array}{c}\text { Nilai Tengah Tingkat } \\
\text { Kehijauan Daun }\end{array}$ \\
\hline Tanpa Mikoriza & $------\mathrm{cm} \mathrm{------}$ & ---- Helai ---- & ------ \%------ \\
Entrophospora sp. Isolat MV 3 & $87,87 \mathrm{c}$ & $11,60 \mathrm{~b}$ & $59,14 \mathrm{a}$ \\
Entrophospora sp. Isolat MV 12 & $88,99 \mathrm{bc}$ & $12,50 \mathrm{a}$ & $61,05 \mathrm{a}$ \\
Glomus sp. IsolatMV 4 & $100,04 \mathrm{a}$ & $12,50 \mathrm{a}$ & $60,91 \mathrm{a}$ \\
Glomus sp.IsolatMV 11 & $96,13 \mathrm{ab}$ & $12,80 \mathrm{a}$ & $61,28 \mathrm{a}$ \\
Glomus sp. Isolat MV 13 & $93,19 \mathrm{abc}$ & $12,30 \mathrm{ab}$ & $58,94 \mathrm{a}$ \\
\hline BNT 5\% & $100,38 \mathrm{a}$ & $12,60 \mathrm{a}$ & $59,31 \mathrm{a}$ \\
\hline NPK 100 \% dosis anjuran & 7,56 & 0,86 & 5,47 \\
NPK 75\% dosis anjuran & $93,73 \mathrm{a}$ & $12,50 \mathrm{a}$ & $60,12 \mathrm{a}$ \\
\hline BNT 5\% & $95,12 \mathrm{a}$ & $12,60 \mathrm{a}$ & $60,08 \mathrm{a}$ \\
\hline Keterangan
\end{tabular}

Keterangan: Dua nilai tengah yang diikuti dengan huruf yang sama tidak berbeda menurut uji BNT pada $\alpha 5 \%$

Inokulasi FMA pada bibit kelapa sawit berpengaruh terhadap jumlah daun bibit kelapa sawit. Jumlah daun bibit kelapa sawit terbanyak diperoleh pada bibit yang diinokulasi Glomus sp. MV 4 ,tetapi tidak berbeda nyata dengan pemberian seluruh jenis inokulum mikoriza. Jumlah daun terendah pada bibit yang tanpa inokulasi mikoriza, namun tidak berbeda nyata dengan Glomus sp. MV 11. Perlakuan pemupukan NPK pada tidak berpengaruh pada jumlah daun bibit kelapa sawit. Pada tigkat kehijauan daun Inokulasi FMA, dosis pupuk NPK, maupun pengaruh interaksi antara keduanya tidak berpengaruh nyata (Tabel 4).

Hasil penelitian menunjukkan bahwa inokulasi FMA pada bibit kelapa sawit berpengaruh terhadap bobot segar tajuk bibit kelapa sawit. Bobot segar tajuk bibit kelapa sawit terbesar diperoleh pada bibit yang diinokulasi Entrophospora sp. Isolat MV 12 dan Glomus sp. Isolat MV 13, berbeda nyata dengan tanpa mikoriza, Entrophospora sp. Isolat MV 3 dan Glomus sp. IsolatMV 11. Perlakuan pupuk NPK tidak berpengaruh terhadap bobot segar tajuk bibit kelapa sawit (Tabel 5). Pada variabel pengamatan bobot kering tajuk, inokulasi FMA meningkatkan bobot kering tajuk bibit kelapa sawit. Bobot kering tajuk bibit kelapa sawit terbesar diperoleh pada bibit yang diinokulasi Glomus sp. Isolat MV 4, Entrophospora sp. Isolat MV 12 dan Glomus sp. Isolat MV 13 menghasilkan bobot kering tajuk yang lebih tinggi dibandingkan tanpa inokulasi FMA berbeda nyata dengan tanpa mikoriza dan Entrophospora sp. Isolat MV 3, sedangkan bobot kering tajuk terendah terdapat pada bibit yang tidak diinokulasikan FMA serta tidak berbeda nyata dengan Glomus sp. Isolat MV 11. Perlakuan pemupukan NPK pada dosis $100 \%$ dosis ajuran menghasilkan bibit yang lebih tinggi dibandingkan perlakuan pupuk 75\% dari dosis anjuran (Tabel 5).

Marschner dan Dell (1994) menyatakan bahwa FMA memiliki peranan penting dalam meningkatkan pertumbuhan tanaman dengan cara meningkatkan serapan hara melalui perluasan permukaan area serapan. Fungi mikoriza Arbuskular membantu penyerapan unsur hara melalui hifahifa eksternalnya yang berasosiasi dengan akar tanamn inangnya, sehingga tanaman dapat menyerap 
Retta Ramadhina Rias: Seleksi Lima Isolat Fungi Mikoriza Arbuskular untuk Pembibitan Kelapa Sawit...

air dan unsur hara di daerah non-rhizosfir. Menurut Nugroho (1990), meningkatnya penyerapan ionion lainnya dari tanah sehingga makin banyaknya unsur hara yang diserap oleh tanaman dapat menaikkan bobot bagian atas tanaman seperti bobot kering tajuk dan bobot segar tajuk.

Tabel 5. Pengaruh perlakuan jenis FMA dan dosis pupuk NPK pada bobot segar tajuk dan bobot kering bibit kelapa sawit umur 9 bulan.

\begin{tabular}{|c|c|c|}
\hline Perlakuan & Nilai Tengah Bobot Segar Tajuk & $\begin{array}{c}\text { Nilai Tengah Bobot Kering } \\
\text { Tajuk }\end{array}$ \\
\hline & ---------------- g ---------------- & 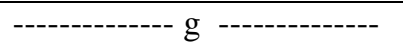 \\
\hline Tanpa Mikoriza & $340,08 \mathrm{c}$ & $93,64 \mathrm{c}$ \\
\hline Entrophospora sp. Isolat MV 3 & $388,52 \mathrm{bc}$ & $101,49 \mathrm{~b}$ \\
\hline Entrophospora sp. Isolat MV 12 & $492,33 \mathrm{a}$ & $116,24 \mathrm{ab}$ \\
\hline Glomus sp. IsolatMV 4 & $437,87 \mathrm{ab}$ & $120,88 \mathrm{a}$ \\
\hline Glomus sp.IsolatMV 11 & $399,05 \mathrm{bc}$ & $110,40 \mathrm{abc}$ \\
\hline Glomus sp. Isolat MV 13 & $476,72 \mathrm{a}$ & $115,82 \mathrm{ab}$ \\
\hline BNT $5 \%$ & 5,47 & 17,04 \\
\hline NPK $100 \%$ dosis anjuran & $426,03 \mathrm{a}$ & $118,01 \mathrm{a}$ \\
\hline NPK $75 \%$ dosis anjuran & $418,82 \mathrm{a}$ & $101,48 \mathrm{~b}$ \\
\hline BNT $5 \%$ & 3,16 & 9,84 \\
\hline
\end{tabular}

Keterangan: Dua nilai tengah yang diikuti dengan huruf yang sama tidak berbeda menurut uji BNT pada $\alpha 5 \%$

Hasil penelitian menunjukkan bahwa inokulasi FMA pada bibit kelapa sawit berpengaruh terhadap bobot segar akar bibit kelapa sawit. Bobot segar akar bibit kelapa sawit terbesar diperoleh pada bibit yang diinokulasi Entrophospora sp. Isolat MV 12 berbeda nyata dengan tanpa mikoriza, Entrophospora sp. Isolat MV 3, dan Glomus sp. Isolat MV 11 tetapi tidak berbeda dengan Glomus sp. Isolat MV 4 dan Glomus sp. Isolat MV 13. Bobot segar akar terendah terdapat pada bibit yang tidak diinokulasikan FMA. Perlakuan pemupukan NPK dosis 100\% menghasilkan bobot segar akar yang lebih tinggi dari dosis ajuran dibandingkan diberikan pupuk 75\% dari dosis anjuran (Tabel 8).

Tabel 8. Pengaruh perlakuan jenis FMA dan dosis pupuk NPK pada persen infeksi akar bibit kelapa sawit umur 9 bulan.

\begin{tabular}{|c|c|c|}
\hline Perlakuan & Nilai Tengah Persen Infeksi Akar & Nilai Tengah Jumlah Spora \\
\hline & ----------- \% & jumlah spora/50 g sampel tanah \\
\hline Tanpa Mikoriza & $63,05 \mathrm{~b}$ & $15,40 \mathrm{c}$ \\
\hline Entrophospora sp. Isolat MV 3 & $85,51 \mathrm{a}$ & $52,50 \mathrm{ab}$ \\
\hline Entrophospora sp. Isolat MV 12 & $90,70 \mathrm{a}$ & $52,40 \mathrm{~b}$ \\
\hline Glomus sp. IsolatMV 4 & $85,87 \mathrm{a}$ & $50,50 \mathrm{~b}$ \\
\hline Glomus sp.IsolatMV 11 & $80,27 \mathrm{a}$ & $60,00 \mathrm{a}$ \\
\hline Glomus sp. Isolat MV 13 & $90,77 \mathrm{a}$ & $52,70 \mathrm{ab}$ \\
\hline BNT $5 \%$ & 12,63 & 7,5 \\
\hline NPK $100 \%$ dosis anjuran & $78,49 \mathrm{~b}$ & $46,90 \mathrm{a}$ \\
\hline NPK $75 \%$ dosis anjuran & 86,90 a & $47,60 \mathrm{a}$ \\
\hline BNT $5 \%$ & 7,29 & 4,37 \\
\hline
\end{tabular}

Keterangan: Dua nilai tengah yang diikuti dengan huruf yang sama tidak berbeda menurut uji BNT pada $\alpha 5 \%$

Inokulasi FMA pada bibit kelapa sawit berpengaruh terhadap bobot kering akar bibit kelapa sawit. Bobot kering akar bibit kelapa sawit terbesar diperoleh pada bibit yang diinokulasi Glomus sp. MV 4 berbeda nyata dengan tanpa mikoriza, tetapi tidak berbeda nyata dengan pemberian jenis FMA lainnya. Bobot kering akar terendah terdapat pada bibit yang tidak diinokulasikan FMA. Perlakuan dosis pupuk tidak berpengaruh terhadap bobot kering akar bibit kelapa sawit (Tabel 6). Hal ini didukung oleh penelitian Safitri (2012) yang menyatakan bahwa tanaman tomat yang diinokulasikan 
dengan berbagai jenis dan dosis FMA memiliki bobot basah akar dan bobot kering akar yang lebih tinggi dibandingkan dengan tanpa inokulasi FMA.

Tabel 6. Pengaruh perlakuan jenis FMA dan dosis pupuk NPK pada bobot segar akar dan bobot kering bibit kelapa sawit umur 9 bulan.

\begin{tabular}{lcc}
\hline \multicolumn{1}{c}{ Perlakuan } & Nilai Tengah Bobot Segar & Nilai Tengah Bobot Kering Akar \\
\hline & Akar & ----------- Helai ------------- \\
Tanpa Mikoriza & $84,64 \mathrm{c}$ & $21,18 \mathrm{~b}$ \\
Entrophospora sp. Isolat MV 3 & $98,73 \mathrm{~b}$ & $25,21 \mathrm{a}$ \\
Entrophospora sp. Isolat MV 12 & $110,53 \mathrm{a}$ & $23,65 \mathrm{a}$ \\
Glomus sp. IsolatMV 4 & $107,12 \mathrm{ab}$ & $26,75 \mathrm{a}$ \\
Glomus sp.IsolatMV 11 & $98,67 \mathrm{~b}$ & $26,14 \mathrm{a}$ \\
Glomus sp. Isolat MV 13 & $100,89 \mathrm{ab}$ & $25,64 \mathrm{a}$ \\
\hline BNT 5\% & 11,55 & 4,00 \\
\hline NPK 100 \% dosis anjuran & $105,19 \mathrm{a}$ & $25,14 \mathrm{a}$ \\
NPK 75\% dosis anjuran & $95,01 \mathrm{~b}$ & $24,39 \mathrm{a}$ \\
\hline BNT 5\% & 6,67 & 2,30 \\
\hline Ketrangan Dua nili
\end{tabular}

Keterangan: Dua nilai tengah yang diikuti dengan huruf yang sama tidak berbeda menurut uji BNT pada $\alpha 5 \%$

Inokulasi FMA pada bibit kelapa sawit berpengaruh terhadap jumlah akar primer bibit kelapa sawit. Jumlah akar primer bibit tertinggi diperoleh pada bibit yang diinokulasi Glomus sp. Isolat MV 13 dan Glomus sp. IsolatMV 4 yang berbeda nyata dengan tanpa mikoriza dan Glomus sp. MV 11, sedangkan jumlah akar primer terendah terdapat pada bibit yang tidak diinokulasikan FMA dan tidak berbeda nyata dengan Entrophospora sp. Isolat MV 3, Entrophospora sp. Isolat MV 12, dan Glomus sp. Isolat MV 11. Perlakuan pupuk NPK pada jumlah akar primer bibit kelapa sawit (Tabel7).

Hasil penelitian menunjukkan bahwa inokulasi FMA pada bibit kelapa sawit berpengaruh terhadap volume akar bibit. Volume akar bibit kelapa sawit tertinggi diperoleh pada bibit yang diinokulasi Glomus sp. Isolat MV 4, Glomus sp. Isolat MV 13, dan Entrophospora sp. Isolat MV 12 berbeda nyata dengan tanpa mikoriza. Perlakuan pupuk NPK pemupukan tidak berpengaruh nyata terhadap volume akar bibit kelapa sawit (Tabel 7).

Tabel 7. Pengaruh perlakuan jenis FMA dan dosis pupuk NPK pada jumlah akar primer dan volume akar bibit kelapa sawit umur 9 bulan.

\begin{tabular}{lcc}
\hline \multicolumn{1}{c}{ Perlakuan } & $\begin{array}{c}\text { Nilai Tengah Jumlah Akar } \\
\text { Primer }\end{array}$ & Nilai Tengah Volume Akar \\
\hline Tanpa Mikoriza & $21,00 \mathrm{~b}$ & $116,00 \mathrm{c}$ \\
Entrophospora sp. Isolat MV 3 & $22,10 \mathrm{ab}$ & $130,00 \mathrm{bc}$ \\
Entrophospora sp. Isolat MV 12 & $23,20 \mathrm{ab}$ & $152,00 \mathrm{ab}$ \\
Glomus sp. IsolatMV 4 & $24,00 \mathrm{a}$ & $154,00 \mathrm{a}$ \\
Glomus sp.IsolatMV 11 & $21,40 \mathrm{~b}$ & $131,00 \mathrm{bc}$ \\
Glomus sp. Isolat MV 13 & $24,30 \mathrm{a}$ & $152,00 \mathrm{ab}$ \\
\hline BNT 5\% & 2,22 & 22,816 \\
\hline NPK 100 \% dosis anjuran & $22,60 \mathrm{a}$ & $140,00 \mathrm{a}$ \\
NPK 75\% dosis anjuran & $22,73 \mathrm{a}$ & $138,33 \mathrm{a}$ \\
\hline BNT 5\% & 1,28 & 13,17 \\
\hline
\end{tabular}

Keterangan: Dua nilai tengah yang diikuti dengan huruf yang sama tidak berbeda menurut uji BNT pada $\alpha 5 \%$

Inokulasi FMA pada bibit kelapa sawit berpengaruh terhadap persen infeksi akar bibit. Persen infeksi akar pada bibit kelapa sawit yang diinokulasikan FMA berbeda nyata dengan tanpa mikoriza. Persen infeksi akar terendah terdapat pada bibit yang tidak diinokulasikan FMA. Perlakuan 
pemupukan NPK berpengaruh nyata terhadap persen infeksi akar. Persen infeksi akar lebih baik diperoleh pada tanaman yang di berikan dosis pupuk NPK 75\% dari dosis ajuran (Tabel 8).

Fakuara (1998) menyatakan percobaan dalam pot tanah yang tidak steril memungkinkan adanya FMA didalamnya. Oleh sebab itu diperlukan melakukan sterilisasi media tanam yang lebih steril guna menekan FMA endogenus yang dikhawatirkan bersifat antagonis. Hal ini didukung oleh hasil penelitian Safitri (2012) yang menemukan bahwa pada tanaman tomat yang diberikan perlakuan tanpa mikoriza juga mengalami infeksi akar sebesar 26,67\%.

Inokulasi FMA pada bibit kelapa sawit berpengaruh terhadap jumlah spora dalam tanah yang telah ditanami bibit kelapa sawit. Jumlah spora terbanyak diperoleh pada bibit yang diinokulasi Glomus sp. MV 11 berbeda nyata dengan tanpa mikoriza, Entrophospora sp. MV 12 dan Glomus sp. MV 4. Jumlah spora terendah terdapat pada bibit yang tidak diinokulasikan FMA. Perlakuan pupuk NPK tidak berpengaruh nyata terhadap jumlah spora.

\section{KESIMPULAN}

Hasil penelitian menunjukkan bahwa (1) Seluruh jenis FMA yang diujikan dapat meningkatkan pertumbuhan bibit kelapa sawit dibandingkan tanpa FMA kecuali Glomus sp. Isolat MV 11, (2) pemberian dosis pupuk NPK 100\% dari dosis anjuran menghasilkan pertumbuhan terbaik bibit kelapa sawit pada variabel bobot segar akar, volume akar, bobot segar tajuk, bobot kering akar, bobot kring tajuk, dan tingkat kehijauan daun, (3) respon pertumbuhan bibit kelapa sawit terhadap inokulasi FMA tidak ditentukan oleh dosis pupuk NPK yang diberikan, (4) tidak terdapat dosis optimum pupuk NPK untuk masing-masing jenis FMA yang digunakan.

\section{DAFTAR PUSTAKA}

Anas, I. 1989. Biologi Tanah dalam Praktek. Direktorat Jendral Pendidikan Tinggi Pusat Antar Universitas Bioteknologi. IPB. Bogor.

Direktorat Jenderal Perkebunan. 2012.Tabel Produksi, Luas Areal dan Produktivitas Perkebunan di Indonesia. Direktorat Jenderal Perkebunan, Jakarta.

Fakuara, Y. M. 1998. Mikoriza, Teori, dan Kegunaan dalam Praktek. Pusat Antar Universitas IPBLembaga Sumber Daya Informasi IPB. Bogor.

Fauzi, Y., Y. E Widyastuti., I. Satyawibawa, dan R. H. Paeru. 2012. Kelapa Sawit. Penebar Swadaya. Jakarta. 236 hlm.

Hardjowigeno, S. 1993. Klasifikasi tanah dan Pedogenesis. Akademika Pressindo. Jakarta. $320 \mathrm{hlm}$.

Kementrian Pertanian. 2010. Outlook Komoditas Pertanian Perkebunan. Pusat Data dan Informasi Pertanian Kementerian Pertanian. Jakarta. 189 hlm.

Marschner, H., and B. Dell. 1994. Nutrient uptake in mycorrhizal symbiosis. In A. D. Robson, L.K. Abbott, and N. Malajczuk. Management of Mychorrhizas in Agiculture, Horticulture, and Forestry. Pp 89-102. Kluwer Academic Publishers. Netherlands 
Jurnal Penelitian Pertanian Terapan

Nugroho, S. G. 1990. Tanggapan Tanaman Jagung Hibrida Pioness teradap Inokulasi MVA dan Pemupukan P pada Tanah Ultisol Rangkas Bitung Banten. Laporan penelitian. Kerjasama AARP-Dikti. Jakarta. 54 hlm.

Safitri, N. 2012. Pengaruh Berbagai Jenis dan Dosis Fungi Mikoriza Arbuskular pada Pertumbuhan dan Produksi Tomat (Lycopersicum esculentum Mill.). Skripsi Universitas Lampung. Bandar Lampung. $81 \mathrm{hlm}$.

Simanungkalit, R. D. M. 2004. Fungi Mikoriza Arbuskular di bidang Pertanian. Prosiding. Workshop Mikoriza Teknik Produksi Bibit Tanaman Bermikoriza. Bogor. 